\title{
Coordinative Urban-Rural Solid Waste Management: A Fractional Dual-Objective Programming Model for the Regional Munifcipality of Xiamen
}

\author{
Aili Yang $\mathbb{D}^{1}{ }^{1}$ Xiujuan Chen $\mathbb{D}^{1,2}$ Guohe Huang, ${ }^{1,2}$ Shan Zhao, \\ Xiajing Lin, ${ }^{1,2}$ and Edward Mcbean ${ }^{1,5}$ \\ ${ }^{1}$ Key Laboratory of Environmental Biotechnology, Xiamen University of Technology, Xiamen, 361024, China \\ ${ }^{2}$ Faculty of Engineering and Applied Science, University of Regina, Regina, SK S4S 0A2, Canada \\ ${ }^{3}$ Shandong Key Laboratory of Water Pollution Control and Resource Reuse, School of Environmental Science and Engineering, \\ Shandong University, Qingdao, 266237, China \\ ${ }^{4}$ Shandong Wuzhou Detection Co., Ltd, Jining 273200, China \\ ${ }^{5}$ School of Engineering, University of Guelph, Guelph, ON N1G 2W1, Canada
}

Correspondence should be addressed to Xiujuan Chen; chen240x@uregina.ca

Received 24 October 2018; Revised 23 February 2019; Accepted 10 March 2019; Published 22 April 2019

Academic Editor: Ching-Ter Chang

Copyright (C) 2019 Aili Yang et al. This is an open access article distributed under the Creative Commons Attribution License, which permits unrestricted use, distribution, and reproduction in any medium, provided the original work is properly cited.

A linear fractional programming based solid waste management planning model was proposed and applied to support the planning of urban-rural solid waste management in Xiamen, China. The model could obtain the best system efficiency while solving the tradeoff between economic and environmental objectives. It aimed to effectively address the urban and rural solid waste management planning through minimizing the system cost and optimizing system efficiency in the developed model framework. Through the model, the optimal waste flow for each facility was obtained, and the problem of overburdened landfill in Xiamen's urban and rural solid waste management system was solved. The solutions for waste allocation and facility capacity expansion were provided for Xiamen's urban and rural solid waste management. The planning results showed that about $42.44 \times 10^{6}$ tons of waste would be diverted to other facilities from landfills over the planning period of 2018-2032, and the waste diversion rate would reach $97 \%$, which would greatly reduce the burden on landfills. The economic efficiency of waste diversion would be $5.07 \times 10^{3}$ ton per $10^{6}$ RMB. All the capacities of Xiamen's urban and rural solid waste management facilities including incinerators, composting plant, and landfills should be expanded because of increasing waste production rate.

\section{Introduction}

With the gradual acceleration of the urbanization process and the continuous improvement of people's living and consumption levels in China, the production of solid waste has increased dramatically in the past two decades [1]. The annual growth rate of solid waste has exceeded $10 \%$ in China, and a number of cities and towns are surrounded by more than 70 billion tons of solid waste, covering an area of more than 500 million square meters. In the development process of urban and rural integration, the scope of city is expanding, many villages and towns are being gradually transformed into new urban areas, and the boundaries between rural and urban areas are becoming blurred. The development of the city is largely based on the development of the rural areas. Whether industry feeds agriculture or the city supports the rural areas, to achieve integration, the relationship between economic and environmental interests should be coordinated. However, the solid waste management and treatment method in these new areas is still traditional storage or landfilling, which has not yet been included in the planning [2]. What is more, the situation of gross urban and rural solid waste growth is grim. The problems of "garbage siege" and "garbage to the countryside" have become serious obstructions for the urban-rustic sustainable development, since this solid waste could potentially result in severity waste of urban and rural 
land resources, pollutions of soil, groundwater and air, and ecological disruption [3-5]. For instance, limited availability in land resources in specific areas such as the isolated island communities is restricted to the solid waste disposal in landfills and composting $[6,7]$. Landfill leachate can contaminate groundwater with potentially hazardous chemicals $[8,9]$. Particularly, Tetrachloroethylene (PCE) and Trichloroethylene (TCE) produce toxic and carcinogenic intermediates and are commonly found mixed together in the groundwater of hazardous waste disposal sites, especially in urban industrial areas [10]. Additionally, greenhouse gases may be produced during landfilling, composting, and incineration processes [11-13]. Furthermore, in light of their highly variable nature, incineration may lead to the generation of dioxin, and landfill and composting may lead to the generation of odor and the growing serious ecological environmental problems, especially where domestic waste and industrial wastes coexist $[14,15]$. Thus, the effective solid waste management planning issues have received extensive attention [16].

In the planning of solid waste management system, waste managers need to consider some necessary issues such as solid waste allocation and equipment capacity expansion [17]. Previously, a number of optimization models were proposed for waste management. For instance, Akbarpour Shirazi et al. (2016) designed a linear mathematical programming model for integrated solid waste management in Tehran [18]. Yadav et al. (2017) employed an interval optimization approach to find optimal solutions for a facility location model, where the parameters were expressed as interval values with deterministic lower and upper bounds [19]. Garibay-Rodriguez et al. (2018) proposed a multiperiod approach to municipal solid waste network management considering waste reduction processes and landfill [20]. Jia et al. (2018) established a construction and demolition waste management model that used the approach of integrating system dynamics and grey model theory to reduce the amount of illegally dumped waste [21]. Hoang et al. (2018) presented a multiobjective optimization model to obtain the efficient waste-flow-allocation and the optimal capacity of disposal facilities in Hoi An city, Vietnam [22]. Generally, the above models were effective to waste management; however, they usually combined objectives of multiple aspects into a single measure on the basis of subjective assumptions, where the identification of weighting factors or economic indicators was considered difficult. Moreover, these methods focused on system inputs and outputs, without optimization for the system efficiency represented as output/input ratios [23]. Furthermore, it is difficult to obtain the best system efficiency while solving the tradeoff between economic and environmental objectives [24-26]. Besides, there are various uncertainties in actual operation [27, 28]. First of all, building too many landfills will take up too much land resource because of huge land occupation and also cause long-term environmental pollutions in large area. Hence, waste diversion that means diverting solid waste to other management facilities for incineration or recycling will greatly relieve the pressure of landfilling, extend the use life of the landfill, and mitigate environmental pollution. However, this may result in higher system costs because of higher operation costs [29].
Second, landfills have a total capacity limit, while incinerators and composting plants have daily processing capacity limits, and they also face requirements of environmental friendliness in the disposal process, such as standard discharge of waste in incineration station and odor control in the landfill. This will inevitably lead to insufficient facility capacities to meet the whole demand for solid waste management and disposal in the future. Thus, the multiperiod and multifacility expansion planning is an unavoidable problem in the long-term solid waste management planning. In addition, as facility capacity expands, the relationship between solid waste production and available facility capacity will change over time; the corresponding solid waste allocation scheme will also vary from schedule to schedule [30]. Therefore, from the perspective of long-term planning, how to maximize the amount of diverted solid waste with minimized system cost through effective solid waste allocation with spatial-temporal characteristic is one of the most important issues for optimizing the solid waste management planning.

In order to address the problem above, the linear fractional programming (LFP) method can be used as an important planning tool. It is a suitable method to deal with the conflict between system cost and environmental objective during the modeling process and has been applied for management planning in many areas such as environmental engineering system, energy system, and irrigation system [31-34]. For example, Zhu and Huang (2013) applied LFP for capacity-expansion planning of electric power systems; this approach can balance conflicting objectives efficiently compared with traditional least-cost models [35]. Chen et al. (2016) developed a nonlinear fractional programming approach based on LFP for addressing the environmentaleconomic power dispatch problems, which showed that this approach was obviously superior to other approaches for realizing a more environment-friendly and cost-effective scheme [36]. Zhang and Guo (2017) integrated fuzzy credibilityconstrained programming into LFP optimization framework, which could balance the economic and resources objectives directly and analyze system efficiency [37]. Wang et al. (2018) proposed a multistage joint-probabilistic left-handside chance-constrained fractional programming (MJCFP) approach based on LFP, which applied to one Canadian electric power system for dealing with the tradeoff between economic development and climate change mitigation [38]. The above research indicates that LFP, as an effective method for dealing with multiobjective problems, is basically suitable to reflect the complexities of an environmental-economic perspective.

Therefore, the aim of this study is to develop a coordinative solid waste management planning model based on linear fractional programming and apply it to support the coordinative urban-rural solid waste management planning in Xiamen, China. There are many villages and towns within the jurisdiction of Xiamen area. The Xiamen government is vigorously developing urban and rural cooperation and urbanization, and it is urgent to solve the problem of solid waste management in urban and rural areas. In order to prevent the situation that solid waste in some urban and rural areas is still independently disposed, a comprehensive 
utilization and disposal plan should be formulated from the perspective of waste recycling and environmental control. The proposed model will maximize the system efficiency of solid waste management through maximizing the diverted waste flow to other disposal facilities outside the landfill while minimizing system cost. The solutions of waste flow allocation and facility expansion will be obtained and analyzed for the urban-rural solid waste management planning in Xiamen. The results in this study are expected to provide a decision support for the long-term urban-rural solid waste management in Xiamen.

\section{Materials and Methods}

2.1. Urban-Rural Solid Waste Management in Xiamen. Xiamen covers an area of about $1,573.16 \mathrm{~km}^{2}$, mainly including six districts: Siming District (SM), Huli District (HL), Jimei District (JM), Haicang District (HC), Tong'an District (TA), and Xiang'an District (XA), as shown in Figure 1. The total population of Xiamen is about 3.9 million currently, and it is expected to reach about 5 million in 2020 . The population distribution is about 1,006,000 in Huli District, 983,000 in Siming District, 633,000 in Jimei District, 536,000 in Tongan District, 327,000 in Xiang'an District, and 325,000 in Haicang District [39, 40]. From 2011 to 2015, the average annual population growth rate was about $1.6 \%[39,40]$. In 2015, the total solid waste production in Xiamen was about $1.4654 \times$ $10^{6}$ tons, and the daily production was about 4,016 tons [41]. In recent years, due to the growth of population, the improvement of living standards, and the development of tourism, the solid waste production continues to grow rapidly, and the annual growth rate is up to $9.3 \%$ [41]. According to government statistics, it is reported that Xiamen's annual growth rates of population and solid waste production are the largest in Fujian Province, and this trend will be maintained in the next few years [41].

Xiamen as a waste classification pilot has achieved initial success. After effective classification, a part of solid waste in Xiamen may get recycling, other incineration, and the rest for the landfill. At present, the urban-rural solid waste management system in Xiamen consists of two waste transfer stations, three incinerators, one composting plant, and two landfills (Figure 1 and Table 1). The two waste transfer stations [i.e., Huli waste transfer station (TS1) and Jimei waste transfer station (TS2)] are used to collect, classify, and recycle waste from districts and then compress and transfer the waste to disposal facilities. The composting plant is a newly-built facility and will be used in 2019. The western landfill (LD1) in Haicang district is still under construction and has not yet been put into use [41]. The only landfill currently in use is the eastern landfill (LD2) in Xiang'an district. Therefore, the current urban-rural solid waste distribution mode is that the waste from Siming District is transported to the nearest Houkeng incinerator (IN3), and the remaining waste in Siming District and the waste in Huli District are shipped to eastern landfill; waste from Jimei District and Haicang District is firstly transported to the western incinerator (IN1) in Haicang District for incineration, and the remaining

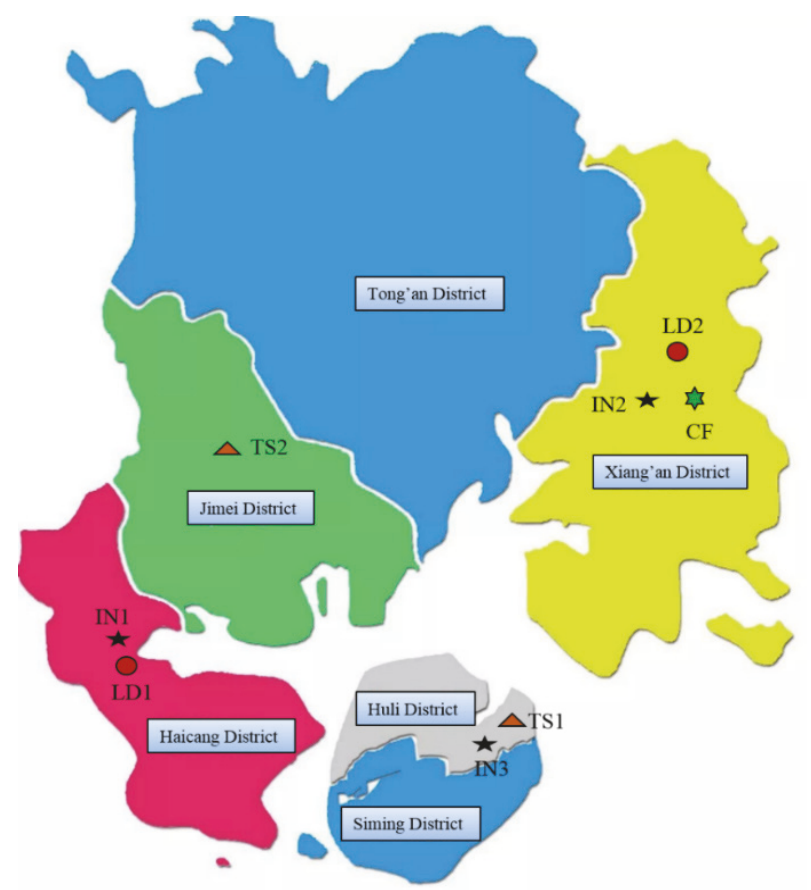

FIgURE 1: Solid waste management system of Xiamen.

waste is transported to eastern landfill for disposal; all waste from Tongan District and Xiang'an District is transported to eastern incinerator (IN2) and eastern landfill [41]. The current situation of urban-rural solid waste management of Xiamen in 2018 is summarized in Table 2. In this case, eastern landfill is applied to dispose more than $60 \%$ of solid waste. Its service life will be severely shortened due to the continuous increase in solid waste production. According to the current urban-rural solid waste distribution mode, the capacity of eastern landfill can only be used for another 5 years. Longterm overload operation and prolonged operation time have increased the treatment difficulties of generated sewage and odor, which has caused negative effects on the surrounding environment. Therefore, Xiamen has set a target in which more than $60 \%$ of solid waste should be diverted from landfills to extend the service life of landfills, and the diversion rate should finally reach over $75 \%$. It is claimed that the gas emission from incinerator has reached the latest EU 2010 standards in Xiamen, and the heat generated by incineration can be converted into electricity through steam and merged into the national grid. In this study, the establishment of a coordinative solid waste management system planning will consider the diversion strategy of solid waste to other disposal facilities to achieve the effective long-term planning of Xiamen's urban-rural solid waste management.

\subsection{Modeling Formulation of Linear Fractional Solid Waste} Management Planning Model for Xiamen. Before formulating linear fractional solid waste management planning model for Xiamen, methods of linear fractional programming and mixed-integer linear programming are introduced. 
TABLE 1: Solid waste management facilities of Xiamen.

\begin{tabular}{lc}
\hline Facility & Existing capacity \\
\hline Huli Waste Transfer Station (TS1) & 1,200 ton/day \\
Jimei Waste Transfer Station (TS1) & 600 ton/day \\
Western Incinerator (IN1) & 600 ton/day \\
Western Landfill (LD1) & 0 \\
Eastern Incinerator (IN2) & 600 ton/day \\
Eastern Landfill (LD2) & $\sim 4.4 \times 10^{6}$ ton \\
Eastern Composting Plant (CF) & 750 ton/day \\
Houkeng Incinerator (IN3) & 400 ton/day \\
\hline
\end{tabular}

Linear Fractional Programming. Linear fractional programming model is useful for analyzing system efficiency in environmental system management planning [23]. A typical linear fractional programming model can be expressed as follows [35]:

$$
\operatorname{Max} f(X)=\frac{C X+\alpha}{D X+\beta}
$$

subject to

$$
\begin{aligned}
A X & \leq B \\
X & \geq 0
\end{aligned}
$$

where, $\boldsymbol{X}$ denotes a vector of decision variables, $X \in\{R\}^{n \times 1}$, and $C, D \in\{R\}^{1 \times n} ; \alpha$ and $\beta$ are constants; $\boldsymbol{A}$ denotes a vector of coefficients in constraint.

Mixed-Integer Linear Programming. In order to deal with the capacity expansions of disposal facilities for Xiamen's urban-rural solid waste management, integer variables will be used to indicate whether the expansion of specific facilities is needed, and thus the mixed-integer linear programming model is introduced and expressed as follows [42]:

$$
\operatorname{Max} f(\mathrm{x})=C^{T} X
$$

subject to

$$
\begin{aligned}
A X & \leq B \\
X & \geq 0
\end{aligned}
$$

where $\boldsymbol{X}$ denotes a vector of decision variables, $\boldsymbol{C}$ and $\boldsymbol{B}$ are vectors, and $\boldsymbol{A}$ denotes a matrix. The mixed integer linear programming model can handle the variables being limited to integers in Xiamen's solid waste management model, while other variables can be noninteger.

Linear Fractional Solid Waste Management Planning Model for Xiamen. Landfill technology is characterized by simple operation and low cost. However, landfills usually cover large area and may cause serious secondary pollution. For example, the leachate produced from landfill severely pollutes the surrounding groundwater and soil $[9,14]$. The odor generated by the solid waste dump seriously affects the air quality around the site [4]. In addition, the methane gas generated from the solid waste fermentation is not only a greenhouse gas but also a hidden source of dangerous explosion [4, 11]. Therefore, this method is potentially harmful and will bring endless troubles to future generations. Landfilling not only fails to realize the solid waste resource recycling but also is a potential way to keep pollution sources, bringing endless troubles in the future.

Xiamen is devoting many efforts to coordinated development of urban and rural areas in an environmentfriendly way. To strengthen the comprehensive environmental management and sustainable development, it is desired to improve the harmless waste disposal rate in coordinative solid waste management. What is more, Xiamen is facing a serious shortage of land resources, leading to the fact that conservation and intensive use of land are necessary. Thus, it is reluctant to build too many landfills with the above disadvantages. Diverting urban-rural solid waste from landfilling to incineration, composting, and recycling is the only way to achieve waste reduction, harmlessness, and reclamation.

In this study, the objective of the model is to maximize the amount of diversion waste by effectively distributing waste flow and minimize system costs. In order to reflect the dynamic changes of urban-rural solid waste production in Xiamen, the planning period is set as 15 years from 2018 to 2032, and it is divided into three periods in the planning model, each of which is 5 years. In Xiamen's coordinative solid waste management planning model, two kinds of decision variables are included: continuous variables and binary variables. Continuous variables represent urbanrural solid waste allocation flows, including waste flows from administrative districts to waste transfer stations and waste disposal facilities and from waste transfer stations to waste disposal facilities. Binary variables represent a solution for facility capacity expansion, and each facility has a different scale of expansion.

The detailed model is presented as follows:

\section{Ratio Objective}

$$
\begin{aligned}
\text { Max } & f=\frac{\text { Net diverted waste }}{\text { System cost }} \\
& =\frac{(e)}{(a)+(b)+(c)-(d)}
\end{aligned}
$$

(a) Regular waste transportation cost

$$
\begin{aligned}
\sum_{i=1}^{6} & \sum_{j=1}^{6} \sum_{k=1}^{3} L_{k} A_{i j k} T R_{i j k}+\sum_{d=1}^{2} \sum_{j=1}^{6} \sum_{k=1}^{3} L_{k} X_{d j k} T S_{d j k} \\
& +\sum_{d=1}^{2} \sum_{i=1}^{6} \sum_{k=1}^{3} L_{k} T_{d i k} T F_{d i k} \\
& +\sum_{i=1}^{3} \sum_{k=1}^{3} L_{k} F E_{k} F T_{i k}\left(\sum_{j=1}^{6} A_{i j k}+\sum_{d=1}^{2} T_{d i k}\right)
\end{aligned}
$$


TABLE 2: Urban-rural solid waste management of Xiamen in 2018.

\begin{tabular}{lcccccc}
\hline & Production of solid waste & Transferring & Recycling & Incineration & Composting & Landfilling \\
\hline ton/day & 4,797 & 1,800 & 144 & 1,600 & 0.00 & 3,053 \\
$\%$ & 100 & 37.52 & 3.00 & 33.35 & 0.00 & 63.64 \\
\hline
\end{tabular}

$$
+\sum_{k=1}^{3} L_{k} F C_{k} F T_{4 k}\left(\sum_{j=1}^{6} A_{4 j k}+\sum_{d=1}^{2} T_{d 4 k}\right)
$$

(b) Regular facility operational cost

$$
\begin{aligned}
\sum_{i=1}^{6} & \sum_{j=1}^{6} \sum_{k=1}^{3} L_{k} A_{i j k} O C_{i k}+\sum_{d=1}^{2} \sum_{j=1}^{6} \sum_{k=1}^{3} L_{k} X_{d j k} O P_{d k} \\
& +\sum_{d=1}^{2} \sum_{i=1}^{6} \sum_{k=1}^{3} L_{k} T_{d i k} O C_{i k}+\sum_{k=1}^{3} L_{k} F E_{k} O C_{5 k} \\
& +\left[\sum_{j=1}^{6}\left(A_{1 j k}+A_{3 j k}\right)+\sum_{d=1}^{2}\left(T_{d 1 k}+T_{d 3 k}\right)\right] \\
& +\sum_{k=1}^{3} L_{k} O C_{6 k}\left[F E_{k}\left(\sum_{j=1}^{6} A_{2 j k}+\sum_{d=1}^{2} T_{d 2 k}\right)\right. \\
& \left.+F C_{k}\left(\sum_{j=1}^{6} A_{4 j k}+\sum_{d=1}^{2} T_{d 4 k}\right)\right]
\end{aligned}
$$

(c) Facility expansion capital cost

$$
\sum_{i=1}^{4} \sum_{m=1}^{3} \sum_{k=1}^{3} F L K_{i k} U_{i m k}+\sum_{i=5}^{6} \sum_{k=1}^{3} F L K_{i k} V L_{i k}
$$

(d) System revenue from incineration and recycling

$$
\begin{aligned}
& \sum_{k=1}^{3} L_{k} \eta_{k} R E_{1 k}\left(\sum_{i=1}^{3} \sum_{j=1}^{6} A_{i j k}+\sum_{d=1}^{2} \sum_{i=1}^{3} T_{d i k}\right) \\
& +\sum_{k=1}^{3} L_{k}\left(1-\eta_{k}\right) R E_{2 k}\left(\sum_{i=1}^{3} \sum_{j=1}^{6} A_{i j k}+\sum_{d=1}^{2} \sum_{i=1}^{3} T_{d i k}\right) \\
& +\sum_{k=1}^{3} L_{k} R E_{3 k}\left(\sum_{j=1}^{6} A_{4 j k}^{ \pm}+\sum_{d=1}^{2} T_{d 4 k}^{ \pm}\right)
\end{aligned}
$$

(e) Net diverted wastes

$$
\begin{array}{r}
\sum_{k=1}^{3} L_{k}\left(1-F E_{k}\right)\left(\sum_{i=1}^{3} \sum_{j=1}^{6} A_{i j k}+\sum_{d=1}^{2} \sum_{i=1}^{3} T_{d i k}\right) \\
+\sum_{k=1}^{3} L_{k}\left(1-F C_{k}\right)\left(\sum_{j=1}^{6} A_{4 j k}+\sum_{d=1}^{2} T_{d 4 k}\right)
\end{array}
$$

where $d$ denotes waste transfer station, $d=1,2 ; i$ denotes waste disposal facility, $i=1,2,3,4,5,6, i=1,2,3$ for incinerator, $i=4$ for composting facility, $i=5,6$ for landfill; $j$ is district, $j=1,2,3,4,5,6 ; k$ denotes planning time period, $k=1,2,3 ; m$ denotes expansion option for incinerator, $m=1,2,3 ; A_{i j k}$ is waste flow from district $j$ to disposal facility $i$ during period $k$ (ton/day); $X_{d j k}$ is waste flow to waste transfer station $d$ from district $j$ during period $k$ (ton/day); $T_{d i k}$ is waste flow to disposal facility $i$ from transfer station $d$ during period $k$ (ton/day); $L_{k}$ is the length of time period $k$ (day); $O P_{d k}$ is operational cost of waste transfer station $d$ during period $k$ (RMB/ton); $O C_{i k}$ is operational cost of waste disposal facility $i$ during period $k$ (RMB/ton); $T R_{i j k}$ is transportation cost to waste disposal facility $i$ from district $j$ during period $k$ (RMB/ton); $T S_{d j k}$ is transportation cost to waste transfer station $d$ from district $j$ during period $k$ ( $\mathrm{RMB} / \mathrm{ton}) ; T F_{d i k}$ is transportation cost to waste disposal facility $i$ from waste transfer station $d$ during period $k$ (RMB/ton); $F T_{i k}$ is transportation cost for residues to landfill from incinerator and composting plant in period $k(\mathrm{RMB} /$ ton $) ; i=1,2,3,4 ; F E_{k}$ is the residue flow rate from incinerator to landfill (\% of incoming mass to incinerator); $F C_{k}$ is the residue flow rate from composting plant to landfill (\% of incoming mass to composting plant); $F L K_{i k}$ is capital cost for waste disposal facility $i$ expansion in period $k(\mathrm{RMB}) ; U_{i m k}$ is binary variables for identifying whether or not expansion of incinerator and composting plant needs to be undertaken during period $k, i=1,2,3 ; V L_{i k}$ are binary variables for identifying whether or not expansion of landfill needs to be undertaken during period $k, i=5,6$; $R E_{1 k}$ is revenue from recycling in period $k$ ( $\mathrm{RMB} /$ ton); $R E_{2 k}$ is revenue from incineration in period $k$ ( $\mathrm{RMB} /$ ton); $R E_{3 k}$ is revenue from composting in period $k$ ( $\mathrm{RMB} /$ ton); $\eta_{k}$ is recycling rate at composting plant (\% of incoming mass to composting plant); $D G_{i k}$ is diversion rate of waste flow to incinerator and composting plant during period $k$ (\% of all waste generation rate), $i=1,2,3,4$.

Constraints. The constraints are set to reflect the relationships between decision variables and system conditions in the waste management planning model for Xiamen. The content of the constraints specifically includes facility capacity, mass balance, waste diversion rate, facility disposal demand, and capacity expansion. The detailed constraints corresponding to objective function are listed as follows.

(a) For capacity constraints for facilities, each facility has its maximum capacity for waste treatment or disposal. Waste management facilities in the coordinative solid waste management system of Xiamen include waste transfer stations, incinerators, composting plant, and landfills. These constraints are established to make sure that the amount of waste allocated to each facility is less than its highest capacity during the planning period. 
Capacity constraint of waste transfer station:

$$
\sum_{j=1}^{6} X_{d j k} \leq T W_{d k}, \quad \forall d, k
$$

Capacity constraint of landfill:

$$
\begin{aligned}
& \sum_{k=1}^{k^{\prime}} L_{k}\left(\sum_{j=1}^{6} A_{5 j k}+\sum_{d=1}^{2} T_{d 5 k}\right)+\sum_{k=1}^{k^{\prime}} L_{k} F E_{k} \\
& \cdot\left[\sum_{j=1}^{6}\left(A_{1 j k}+A_{3 j k}\right)+\sum_{d=1}^{2}\left(T_{d 1 k}+T_{d 3 k}\right)\right] \leq T L_{1} \\
& +\sum_{k=1}^{k^{\prime}} \Delta T L_{1} V L_{5 k}, \quad \forall k^{\prime}=1,2,3 \\
& \sum_{k=1}^{k^{\prime}} L_{k}\left(\sum_{j=1}^{6} A_{6 j k}+\sum_{d=1}^{2} T_{d 6 k}\right)+\sum_{k=1}^{k^{\prime}} L_{k} F E_{k} \\
& \cdot\left(\sum_{j=1}^{6} A_{2 j k}+\sum_{d=1}^{2} T_{d 2 k}\right)+\sum_{k=1}^{k^{\prime}} L_{k} F C_{k} \\
& \cdot\left(\sum_{j=1}^{6} A_{4 j k}+\sum_{d=1}^{2} T_{d 4 k}\right) \leq T L_{2}+\sum_{k=1}^{k^{\prime}} \Delta T L_{2} V L_{6 k}, \\
& \forall k^{\prime}=1,2,3
\end{aligned}
$$

Capacity constraint of incinerator:

$$
\begin{array}{r}
\left(\sum_{j=1}^{6} A_{i j k}+\sum_{d=1}^{2} T_{d i k}\right) \leq T E_{i}+\sum_{m=1}^{3} \sum_{k=1}^{k^{\prime}} \Delta T E_{i m k} U_{i m k}, \\
i=1,2,3 ; \forall k^{\prime}=1,2,3
\end{array}
$$

Capacity constraint of composting plant:

$$
\begin{aligned}
& \sum_{j=1}^{6} A_{4 j k}+\sum_{d=1}^{2} T_{d 4 k} \leq T C+\sum_{m=1}^{3} \sum_{k=1}^{k^{\prime}} \Delta T C_{m k} U_{4 m k} \\
& \forall k^{\prime}=1,2,3
\end{aligned}
$$

(b) Regarding mass balance constraints, the mass balance constraints describe the balance of waste flows in coordinative solid waste management system. The constraints about material balances at transfer stations and material balances in each district are considered to ensure that all the generated urban-rural solid waste can be disposed through effective management.

$$
\begin{aligned}
\sum_{j=1}^{6} X_{d j k} & =\sum_{i=1}^{6} T_{i d k}, \quad \forall d, k \\
\sum_{i=1}^{6} A_{i j k}+\sum_{d=1}^{2} X_{d j k} & \geq W_{j k}, \quad \forall j, k
\end{aligned}
$$

(c) About waste diversion rate constraint, this constraint reflects the diversion rate from landfills to other facilities based on the urban-rural solid waste management policy in Xiamen in the next 15 years. It is established to ensure that the expected diversion goal can be achieved through system optimization.

$$
\begin{aligned}
& \left(1-F E_{k}\right)\left(\sum_{i=1}^{3} \sum_{j=1}^{6} A_{i j k}+\sum_{d=1}^{2} \sum_{i=1}^{3} T_{d i k}\right) \\
& +\left(1-F C_{k}\right)\left(\sum_{j=1}^{6} A_{4 j k}+\sum_{d=1}^{2} T_{d 4 k}\right) \\
& \geq D G_{k} \sum_{j=1}^{6} W_{j k}, \quad \forall k
\end{aligned}
$$

(d) For disposal demand constraints of incinerators, these constraints represent the requirement of disposal waste for each incinerator in each period. The total amount of waste allocated to each incinerator should be over $70 \%$ of its capacity to make sure that the incinerator will be effectively utilized during the planning horizon.

$$
\begin{array}{r}
\sum_{j=1}^{6} A_{i j k}+\sum_{d=1}^{2} T_{d i k} \geq 0.7\left(T E_{i}+\sum_{m=1}^{3} \sum_{k=1}^{k^{\prime}} \Delta T E_{i m k} U_{i m k}\right), \\
i=1,2,3 ; \forall k^{\prime}=1,2,3
\end{array}
$$

$\sum_{j=1}^{6} X_{d j k} \geq V_{d k}, \quad \forall d, k$

$\sum_{j=1}^{6} A_{i j k}+\sum_{d=1}^{2} T_{d i k} \geq S_{i k}, \quad i=1,2,3 ; \forall k$

$$
\begin{aligned}
0.7\left(T E_{i}+\sum_{m=1}^{3} \sum_{k=1}^{k^{\prime}} \Delta T E_{i m k} U_{i m k}\right) & \geq S_{i k}, \\
i & =1,2,3 ; \forall k^{\prime}=1,2,3
\end{aligned}
$$

(e) Regarding constraints of facility capacity expansion, investments for capacity expansion should be carried out to avoid the insufficiencies of urban-rural solid waste management facilities. According to facility property, expansion for each incinerator and composting plant may occur in any planning period, and expansion for each landfill may only be considered once in the whole planning horizon.

$$
\begin{aligned}
& U_{i m k} \\
& \quad= \begin{cases}1, & \text { if expansion for facility } i \text { is undertaken; } \\
0, & \text { if otherwise }\end{cases}
\end{aligned}
$$




$$
\begin{aligned}
& V L_{i k} \\
& \quad= \begin{cases}1, & \text { if expansion for } \mathrm{f} \\
0, & \text { if otherwise }\end{cases} \\
& \sum_{m=1}^{3} U_{i m k} \leq 1, \quad i=1,2,3 ; \forall k \\
& \sum_{k=1}^{3} V L_{i k} \leq 1, \quad i=5,6
\end{aligned}
$$$$
= \begin{cases}1, & \text { if expansion for facility } i \text { is undertaken } \\ 0, & \text { if otherwise }\end{cases}
$$$$
i=5,6 ; \forall k
$$

(f) Nonnegativity constraints:

$$
\begin{aligned}
& A_{i j k} \geq 0, \quad \forall i, j, k ; \\
& X_{d j k} \geq 0, \quad \forall d, j, k ; \\
& T_{d i k} \geq 0, \quad \forall d, i, k
\end{aligned}
$$

where $T E_{i}$ is the existing capacity of incinerator (ton/day), $i=1,2,3 ; \Delta T E_{\text {imk }}$ is the scale of capacity-expansion option $m$ for incinerator at the beginning of period $k$ (ton/day), $i=$ $1,2,3 ; T L_{1}$ is the existing capacity of landfill 1 (ton); $\Delta T L_{1}$ is the scale of capacity-expansion for landfill 1 (ton); $T L_{2}$ is the existing capacity of landfill 2 (ton); $\Delta T L_{2}$ is the scale of capacity-expansion for landfill 2 (ton); TC is the existing capacity of composting plant (ton); $T W_{d k}$ is the capacity of waste transfer station $d$ in period $k$ (ton/day); $W_{j k}$ is the waste generation rate of district $j$ in period $k$ (ton/day); $V_{d k}$ are the smallest amounts of disposal waste for waste transfer station $d$ in period $k$ (ton/day); $S_{i k}$ are the smallest amounts of disposal waste for incinerator in period $k$ (ton/day), $i=1,2,3$.

Modelling Data. Table 3 shows the urban-rural solid waste production in the six administrative districts of Xiamen for each period. The amount of solid waste generated in each planning period is calculated based on the average annual growth rate of waste generation from 2012 to 2016 in Xiamen. Table 4 includes the operating costs of the facilities, the related costs in waste transfer stations and revenue from waste recycle, composting, and incineration. It can be seen that most of costs and revenues will increase because of economic development. Based on Xiamen's environmental policy, in order to reduce the amount of solid waste disposed in landfills, the planned waste diversion rate in planning period I will exceed $60 \%$, period II will exceed $70 \%$, and period III will exceed $75 \%$ [30]. Table 5 summarizes the waste recycle rate, residue rate, diversion rate, and minimum waste disposal demand in incinerators and transfer stations. The urban-rural solid waste of Xiamen can be divided into five parts: inorganic waste, organic waste, recoverable waste, poisonous and harmful waste, and combustible waste [43]. Among them, recoverable waste refers to waste that is suitable for recycling and reusing, such as paper, plastic, glass, metal, fabrics, and bottles. The smallest amounts of waste disposed in incinerators will increase due to the increasing rates of waste generation and diversion. Owing to the same reasons, the existing capacities of waste disposal facilities will be insufficient and needed to be expanded in the future. For incinerators, three capacity-expansion options will be considered in correspondence to the varying waste diversion policies; as for landfills, capacity expansion will only be undertaken once during the planning period. Table 6 shows the expansion options and related costs for different facilities. Most of the relevant data is offered by the Xiamen Municipal Bureau of Environment Protection and the Environmental Health Management Office in Xiamen Municipal Bureau of Parks and Woods [39-41, 44]. Other data are derived from relevant literature [16, 30].

\section{Result Analysis and Discussion}

3.1. Planning Solution for Waste Flow Allocation. In Xiamen, there are three options for coordinative solid waste management due to the capacity limitations of the two waste transfer stations. The solid waste will be transported to (1) waste transfer stations and then to waste disposal facilities; (2) incinerators or the composting plant, the residues will be shipped to the landfills; and (3) landfills directly. Because of spatiotemporal changes in waste production, the coordinative solid waste distribution modes will be different in different planning periods.

3.1.1. Planning Solution for Waste Allocation Flow in Period I. Figure 2 shows the results of the waste allocation in planning period I. From Figure 2, all the solid waste (1,238 ton/day) from Siming District will be transported to the Huli waste transfer station (TS1) located in Huli District. The remaining capacity of the Huli waste transfer station (162 ton/day) will be used to receive the waste from Huli District, while the remaining solid waste of Huli District will be transported (544 ton/day) to the Jimei waste transfer station (TS2) in Jimei District, and another part of waste (560 ton/day) will be allocated to Houkeng incinerator (IN3). A portion of the waste (156 ton/day) in Jimei District will be transported first to the Jimei waste transfer station, and the remaining waste (641 ton/day) will be shipped directly to the western incinerator (IN1). All solid waste (409 ton/day) generated from Haicang District will be transported to western incineration station. Most of the waste from Tongan District (629.7 ton/day) will be transported to the composting plant (CF) built in Xiang'an District, and the other small portions of waste (45.3 ton/day) will be transported to the eastern incinerator (IN2). 118.7 and 293.3 tons of waste from Xiang'an District will be transported to the eastern incinerator and the composting plant, respectively. This is because, in all administrative districts, Huli District and Siming District are the closest two districts to Huli waste transfer station, while Jimei District is the closest to Jimei waste transfer station. The western incinerator is located in Haicang District, and the composting plant is located in Xiang'an District, and the eastern incinerator is built in Tong'an District. The waste from these districts will be shipped to their nearest waste management facilities. 
TABLE 3: Urban-rural solid waste production in each district of Xiamen.

\begin{tabular}{lcccccc}
\hline \multirow{2}{*}{ Period } & & \multicolumn{4}{c}{ Solid waste production (ton/day) } \\
& Siming District & Huli District & Jimei District & Haicang District & Tongan District & Xiang'an District \\
\hline Period I & 1,238 & 1,266 & 797 & 409 & 675 & 412 \\
Period II & 1,930 & 1,976 & 1,243 & 638 & 1,053 & 642 \\
Period III & 3,011 & 3,082 & 1,939 & 996 & 1,642 & 1,002 \\
\hline
\end{tabular}

TABLE 4: Operation cost and revenue information of solid waste management facilities.

\begin{tabular}{|c|c|c|c|}
\hline & \multicolumn{3}{|c|}{ Planning period } \\
\hline & Period I & Period II & Period III \\
\hline \multicolumn{4}{|c|}{ Operation cost (RMB/ton) } \\
\hline Incinerator & 183.68 & 188.8 & 195.2 \\
\hline Composting plant & 128 & 134.4 & 140.8 \\
\hline Landfill & 76.8 & 83.2 & 89.6 \\
\hline Waste transfer station & 14.08 & 14.72 & 16 \\
\hline \multicolumn{4}{|c|}{ Revenue from waste transfer station (RMB/ton) } \\
\hline$R e_{1}$ & 117.12 & 121.6 & 128 \\
\hline \multicolumn{4}{|c|}{ Revenue from incinerator (RMB/ton) } \\
\hline $\operatorname{Re}_{2}$ & 67.2 & 70.4 & 73.6 \\
\hline \multicolumn{4}{|c|}{ Revenue from composting plant (RMB/ton) } \\
\hline $\mathrm{Re}_{3}$ & 16 & 19.2 & 22.4 \\
\hline
\end{tabular}

TABLE 5: Solid waste recycle rate, residue rate, transfer rate, and minimum solid waste disposal demand.

\begin{tabular}{|c|c|c|c|}
\hline & \multicolumn{3}{|c|}{ Planning period } \\
\hline & Period I & Period II & Period III \\
\hline \multicolumn{4}{|c|}{ Minimum solid waste demand in transfer station (ton/day) } \\
\hline$V_{l k}$ & 1,200 & 1,200 & 1,200 \\
\hline$V_{2 k}$ & 600 & 1,000 & 1,000 \\
\hline \multicolumn{4}{|c|}{ Minimum solid waste disposal demand in incinerator (ton/day) } \\
\hline$S_{l k}$ & 400 & 750 & 900 \\
\hline$S_{2 k}$ & 400 & 850 & 950 \\
\hline$S_{3 k}$ & 300 & 700 & 800 \\
\hline \multicolumn{4}{|c|}{ Recycle rate in transfer station (\%) } \\
\hline$\eta_{k}$ & 8 & 8.5 & 9 \\
\hline \multicolumn{4}{|c|}{ Residue rate from incinerator $(\%)$} \\
\hline$F E_{k}$ & 30 & 28 & 26 \\
\hline \multicolumn{4}{|c|}{ Residue rate from composting plant (\%) } \\
\hline$F C_{k}$ & 26 & 23 & 22 \\
\hline \multicolumn{4}{|c|}{ Solid waste diversion rate (\%) } \\
\hline$D G_{k}$ & 60 & 70 & 75 \\
\hline
\end{tabular}

The waste allocation mode from waste transfer stations to disposal facilities will be as follows: the waste collected in Huli waste transfer station will be divided into 4 parts for transfer, including 113 ton/day to eastern incinerator, 98 ton/day to Houkeng incinerator, 383.9 ton/day to composting plant, and 805.1 ton/day to western landfill (LD1); the waste collected in Jimei waste transfer station will be divided into 3 parts and transferred to eastern incinerator (143 ton/day), composting plant (143 ton/day), and eastern landfill (LD2) (413.9 ton/day), respectively.

3.1.2. Planning Solution for Waste Allocation Flow in Period II. Figure 3 shows the planning solution for waste allocation flow in period II. During this period, the waste produced in Siming District will be divided into three parts: 362 tons of waste will be transported to Huli waste transfer station every day, and about 1,421.8 ton/day of waste will be allocated to western incinerator, leaving 146.2 ton/day of waste to be shipped to western landfill. 1,038 and 938 ton/day of waste from the Huli District will be transported to Huli waste transfer station and Houkeng incinerator, respectively. The waste generated in Jimei District (1,200 ton/day) will be transported to Jimei waste transfer station. A portion of the solid waste in Haicang District will be allocated to western incinerator (258.2 ton/day), and the other waste will be shipped to western landfill (379.8 ton/day). All the waste from both Tongan District and Xiang'an District will be transported to composting plant for disposal.

The mode of waste allocation from waste transfer stations to disposal facilities in period II is summarized as follows: 910 ton/day of waste from Huli waste transfer station will be transported to eastern incinerator, and 490 ton/day waste will be transferred to western incinerator; the waste in Jimei waste transfer station will be transferred to composting plant ( 455 ton/day) and eastern landfill (745 ton/day). The differences in the waste allocation modes between the first and second planning periods are due to the rapid increase in solid waste production in Xiamen. Compared with the first planning period, the waste production of Jimei District in period II will be greater than the capacity of Jimei waste transfer station. Therefore, Huli waste transfer station can only transfer the waste from the nearest district (Jimei District).

3.1.3. Planning Solution for Waste Allocation Flow in Period III. During period III, the urban-rural solid waste production in Xiamen will continue to increase substantially, and the capacities of some facilities will be expanded. Therefore, compared with planning period II, the waste allocation patterns are different. Figure 4 shows the results of the waste allocation solution in period III. It can be seen that 365.4 and 2,586.2 ton/day of waste generated in Siming District will be allocated to Huli waste transfer station and eastern incinerator, respectively, and the remaining small amount of waste (59.4 ton/day) will be transported to western landfill. The waste from Huli District will be divided into three parts: 1,034.6 tons of waste will be transported to Huli waste transfer station every day, about 707.4 ton/day 
TABLE 6: Expansion option and expansion cost.

\begin{tabular}{|c|c|c|c|c|}
\hline \multirow{2}{*}{ Expansion option } & \multirow{2}{*}{ Expansion capacity } & \multicolumn{3}{|c|}{ Expansion cost $\left(* 10^{6} \mathrm{RMB}\right)$} \\
\hline & & Period I & Period II & Period III \\
\hline \multicolumn{5}{|l|}{ Western Incinerator (IN1) } \\
\hline Option $1(\mathrm{~m}=1)$ & 700 ton/day & 227.2 & 225.28 & 222.72 \\
\hline Option $2(\mathrm{~m}=2)$ & 800 ton/day & 256 & 256 & 256 \\
\hline Option $3(\mathrm{~m}=3)$ & 900 ton/day & 273.28 & 270.592 & 267.008 \\
\hline \multicolumn{5}{|l|}{ Eastern Incinerator (IN2) } \\
\hline Option $1(\mathrm{~m}=1)$ & 600 ton/day & 195.2 & 193.28 & 190.72 \\
\hline Option $2(\mathrm{~m}=2)$ & 700 ton/day & 227.2 & 225.28 & 222.72 \\
\hline Option $3(\mathrm{~m}=3)$ & 750 ton/day & 240 & 237.44 & 234.88 \\
\hline \multicolumn{5}{|c|}{ Houkeng Incinerator (IN3) } \\
\hline Option $1(\mathrm{~m}=1)$ & 400 ton/day & 131.2 & 129.92 & 126.72 \\
\hline Option $2(\mathrm{~m}=2)$ & 540 ton/day & 172.8 & 170.88 & 168.32 \\
\hline Option $3(\mathrm{~m}=3)$ & 600 ton/day & 195.2 & 193.28 & 190.72 \\
\hline \multicolumn{5}{|l|}{ Composting plant (CF) } \\
\hline Option $1(\mathrm{~m}=1)$ & 450 ton/day & 72.32 & 71.68 & 69.76 \\
\hline Option $2(\mathrm{~m}=2)$ & 550 ton/day & 95.36 & 94.08 & 92.8 \\
\hline Option $3(\mathrm{~m}=3)$ & 700 ton/day & 124.8 & 124.16 & 122.24 \\
\hline Western Landfill (LD1) & $8.5 \times 10^{6}$ ton & 54.72 & 53.76 & 53.44 \\
\hline Eastern Landfill (LD1) & $7.0 \times 10^{6}$ ton & 45.12 & 44.8 & 44.48 \\
\hline
\end{tabular}

of waste will be allocated to Jimei waste transfer station, and the remaining 1,340 ton/day of waste will be shipped to Houkeng incinerator. A portion of the waste produced from Jimei District will be allocated to Jimei waste transfer station (492.6 ton/day), and the other waste will be sent to eastern incinerator (1,446.4 ton/day). Waste generated in Haicang District will flow to western incinerator (713.8 ton/day) and western landfill (282.2 ton/day), respectively. Most of the waste from Tong'an District and Xiang'an District (1,579.2 ton/day and 923.4 ton/day) will be transported to composting plant for treatment, and the other small portions (62.8 ton/day and 78.6 ton/day) will be incinerated by eastern incinerator. As for the waste transfer from waste transfer stations to waste disposal facilities, the waste collected by Huli waste transfer station will be, respectively, transferred to eastern incinerator (232 ton/day), composting plant (347.4 ton/day), and eastern landfill (820.7 ton/day); all the waste (about 1,200 ton/day) collected by Jimei waste transfer station will also be transferred to eastern landfill.

3.2. Planning Solution for Facility Expansion. According to the document of Xiamen solid waste pollution prevention and control information [41], the main solid waste disposal methods in Xiamen are landfill and incineration, and a small part is composted and recycled. Currently, the facilities with planned capacity expansion only include eastern incinerator and western incinerator, and both will be added 1,200 ton/day of capacity in the future. The original designed capacity for eastern landfill is 1,600 ton/day, and it is expected to be used until 2038. The eastern landfill is the only landfill that is currently in use in Xiamen, and the planning for its capacity expansion has not been set in Xiamen's solid waste management. However, even if more than $90 \%$ of the waste is diverted to incinerators and the composting plant, the eastern landfill will still be filled at 2023. What is more, to achieve the set waste diversion rate which is more than $75 \%$, the amount of diverted waste will be about 5,611.5 ton/day in period II, whereas the all available capacity of incinerators and composting plant will only be 4,350 ton/day. This means that the total capacity of incinerators and composting plant will be insufficient to deal with the diverted waste, even if the incinerators will be expanded following the current capacity expansion planning. Therefore, all the solid waste management facilities in Xiamen should be expanded to handle the increasing solid waste, and it is necessary to provide the comprehensive planning solutions for facility expansions.

Table 7 summarizes the expansion plans for solid waste management facilities in different planning periods. Figure 5 shows the capacity of each facility at different periods. The results indicate that all solid waste management facilities will be expanded to meet the increasing waste production. During the overall planning period, approximately $42.44 \times 10^{6}$ tons of waste will be diverted from landfills to other facilities, which means that incinerators and the composting plant will handle up to $97 \%$ of waste for Xiamen. Therefore, the amount of diversion waste will exceed the existing capacities of facilities, leading to the capacity expansion. Specifically, the capacity of eastern incinerator will be increased by 700 and 600 ton/day at the beginning of the second and third planning periods, respectively. The processing capacity of Houkeng incinerator will be increased by 540 and 400 ton/day at the beginning of planning periods I and II, respectively. The western incinerator and composting plant will both be expanded at the beginning of each planning period, adding 900 and 700 ton/day of capacity per period. For landfills, 


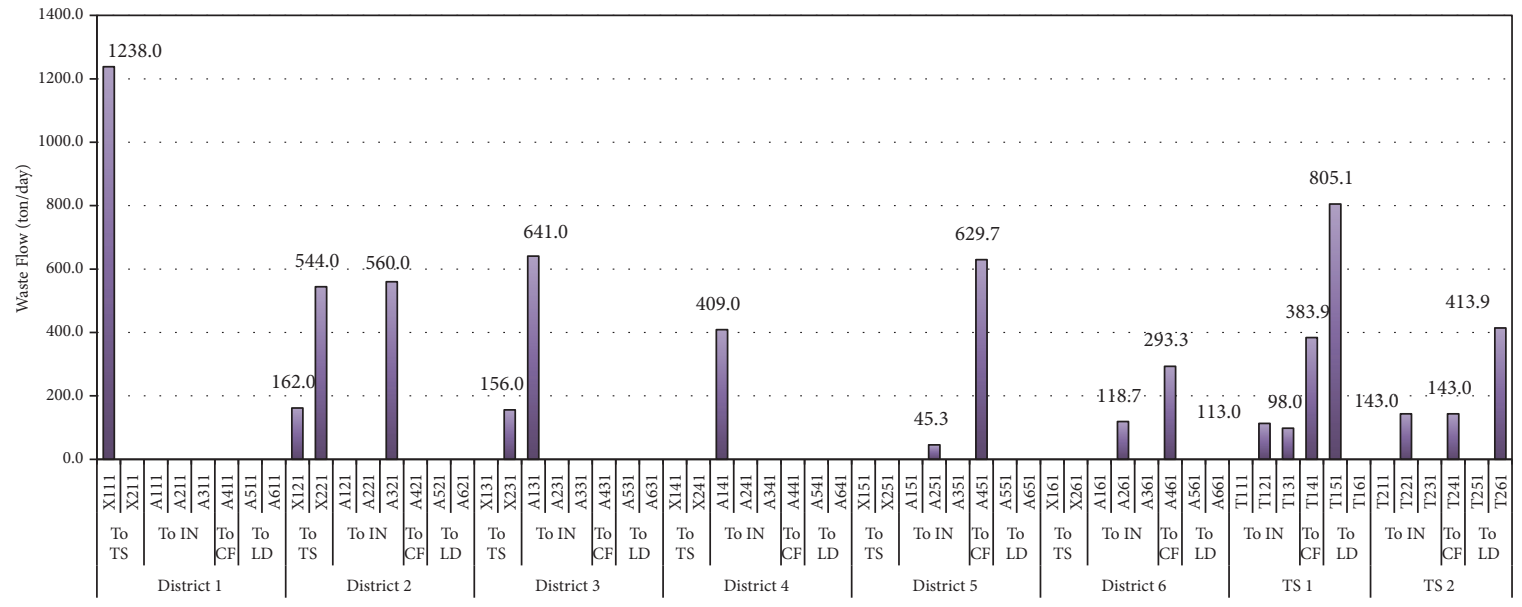

FIgURE 2: The allocation results of solid waste in period I.

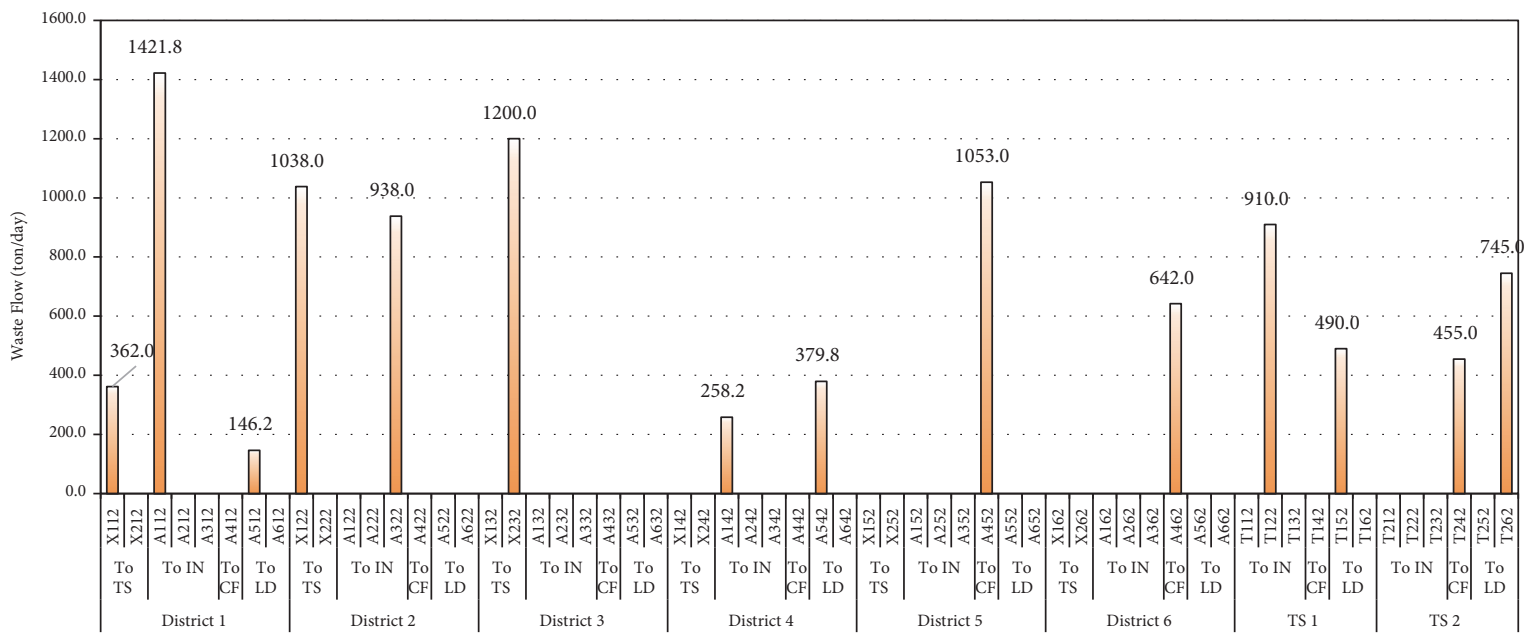

FIgURE 3: The allocation results of solid waste in period II.

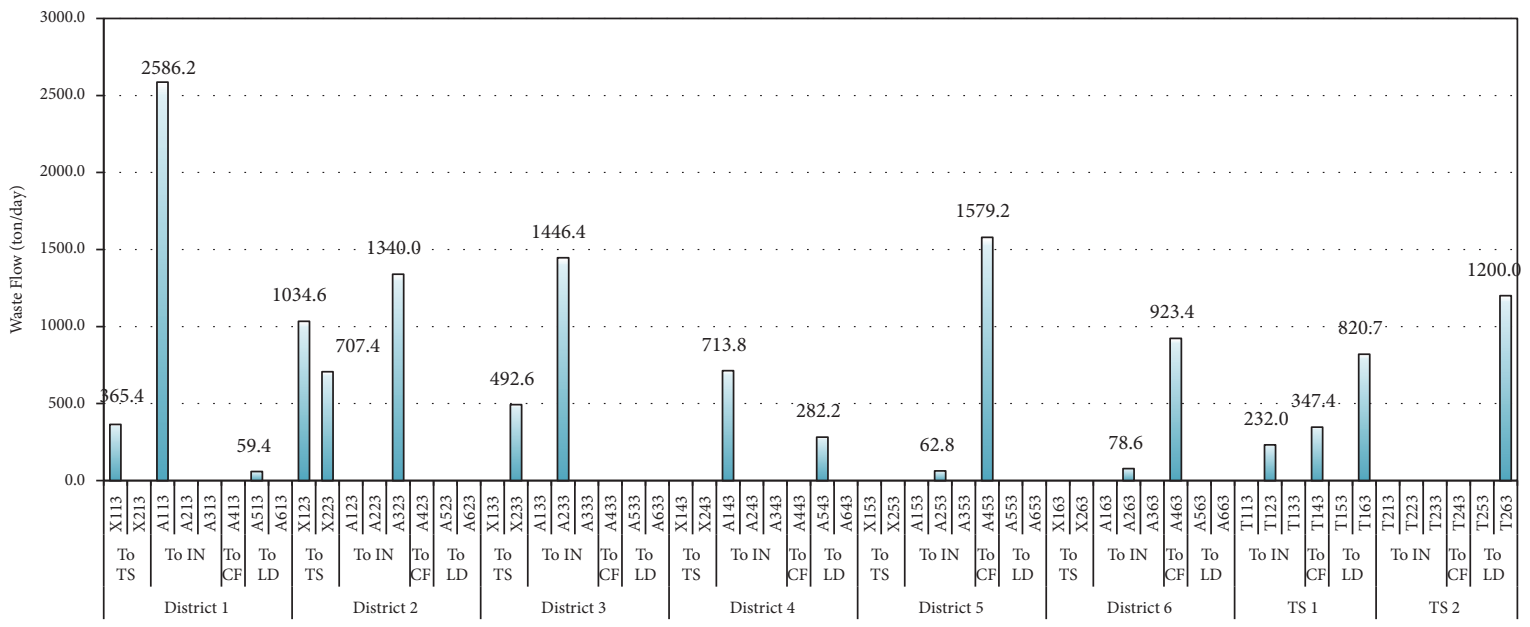

FIGURE 4: The allocation results of solid waste in period III. 


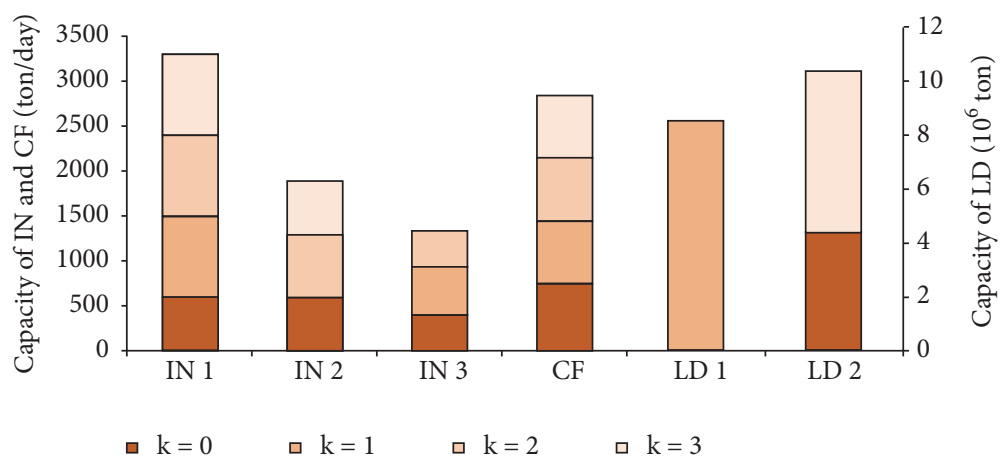

FIGURE 5: Expansion planning scheme for solid waste management facilities.

TABLE 7: Expansion planning for the solid waste facilities.

\begin{tabular}{|c|c|c|c|c|}
\hline \multirow{2}{*}{ Facility } & \multirow{2}{*}{ Existing capacity } & \multicolumn{3}{|c|}{ Expansion capacity } \\
\hline & & Period I & Period II & Period III \\
\hline Western Incinerator (IN1) & 600 ton/day & 900 ton/day & 900 ton/day & 900 ton/day \\
\hline Eastern Incinerator (IN2) & 600 ton/day & 0 ton/day & 700 ton/day & 600 ton/day \\
\hline Houkeng Incinerator (IN3) & 400 ton/day & 540 ton/day & 400 ton/day & 0 ton/day \\
\hline Eastern Composting Plant (CF) & 750 ton/day & 700 ton/day & 700 ton/day & 700 ton/day \\
\hline Western Landfill (LD1) & 0 ton & $8.5 \times 10^{6}$ ton & 0 ton & 0 ton \\
\hline Eastern Landfill (LD2) & $4.4 \times 10^{6}$ ton & 0 ton & 0 ton & $5.95 \times 10^{6}$ ton \\
\hline
\end{tabular}

TABLE 8: Comparison of optimal ratio model and minimum cost model.

\begin{tabular}{lcc}
\hline & $\begin{array}{c}\text { Optimal ratio } \\
\text { model }\end{array}$ & $\begin{array}{c}\text { Minimum cost } \\
\text { model }\end{array}$ \\
\hline System cost $\left(* 10^{6} \mathrm{RMB}\right)$ & $8,372.53$ & $7,923.02$ \\
Waste diversion $\left(* 10^{3}\right.$ ton $)$ & $42,436.18$ & $40,051.49$ \\
Waste diversion rate $(\%)$ & 97.1 & 91.6 \\
$\begin{array}{l}\text { Waste diversion } / \text { cost } \\
\left(10^{3} \text { ton } / 10^{6} \mathrm{RMB}\right)^{\mathrm{a}}\end{array}$ & 5.069 & 5.055 \\
\hline
\end{tabular}

${ }^{a}$ When the total system cost is $10^{6} \mathrm{RMB}, 10^{3}$ tons of waste in total will be diverted to incinerators and the composting plant.

western landfill will have a capacity of $8.5 \times 10^{6}$ tons in the first planning period, and the capacity of eastern landfill will be expanded to $11.4 \times 10^{6}$ tons in planning period III.

\subsection{Comparison between Optimal-Ratio Model and Least-Cost} Model. The optimal-ratio objective in Xiamen's urban-rural solid waste management planning model can be changed into a least-cost objective through setting "Min $f=$ system cost" as objective function, which leads to the least-cost model. Table 8 compares the results obtained from these two models under the same conditions. As shown in Table 8, the system cost obtained from the optimal-ratio model is somehow higher than the least-cost model, which are 8,372.53 $\times 10^{6} \mathrm{RMB}$ and 7,923.02 $\times 10^{6} \mathrm{RMB}$, respectively. However, the waste diversion rate from the optimal-ratio model (97.1\%) is significantly larger than the least-cost model (91.6\%), and the waste diversion per unit of cost obtained from the optimalratio model is also higher than that from the least-cost model. That is to say, in the least-cost model, the ratio of the waste diversion rate to the system cost is smaller, which means that the system efficiency is lower compared to the optimal-ratio model. The reason is that, in the least-cost model, more solid waste will be allocated to landfills due to lower operating costs. In comparison, more solid waste will be diverted to incinerators and composting plant in the optimal-ratio model. Incinerators and composting plant will be operated at their full capacities during the planning period. The amount of diversion waste from landfills will be maximized, significantly extending the useful life of the landfills. The population growth in Xiamen is extremely rapid, and Xiamen is also facing serious land scarcity problems. Thus, the effective management planning of urban-rural solid waste has important practical significance for Xiamen. Landfills are under tremendous pressure to deal with solid waste currently, which also results in environmental pollution in surrounding areas. It is necessary to divert waste to other waste disposal facilities as much as possible. Compared to the least-cost model, the optimal-ratio model is more efficient and suitable for the management planning of urban-rural solid waste in Xiamen. Through the measurement of system efficiency, it is possible to systematically provide more information on the relationship between multiple input factors and system standards and more effectively solve the sustainable development of urban-rural solid waste management in Xiamen.

\section{Conclusions}

In this study, a linear fractional based coordinative solid waste management planning model was developed and employed 
for the sustainable long-term planning of urban-rural solid waste management system in Xiamen area. The model could obtain the best system efficiency for solid waste management while solving the tradeoff between economic and environmental objectives. The results of the model showed that up to $97 \%$ of the solid waste in Xiamen will be diverted from landfills to incinerators and the composting plant, greatly reducing the burden on landfills. Results obtained from this study would be useful for providing decision-making supports to remove the obstructions of solid waste management for Xiamen's urban-rustic sustainable development from 2018 to 2032, as these results can help (i) give the optimal waste allocation scheme to realize the comprehensive operation of urban-rural solid waste disposal-routing patterns, (ii) plan capacity expansion of waste management facilities, (iii) optimize the system efficiency associated with maximal waste diversion rate, and (iv) mitigate the environmental pollutions caused by irrelevantly waste management.

\section{Data Availability}

(1) The [existing capacity of each solid waste management facility, waste production, facility operation cost and revenue, waste recycle rate, facility residue rate, waste transfer rate, facility minimum solid waste disposal demand, facility expansion option, and expansion cost in Xiamen] data used to support the findings of this study are included within the article. (2) The [waste transportation cost] data used to support the findings of this study are available from the corresponding author upon request.

\section{Conflicts of Interest}

The authors declare that there are no conflicts of interest regarding the publication of this paper.

\section{Acknowledgments}

This research was supported by funds from Xiamen Science and Technology Project (3502Z20179035), Key Laboratory of Environmental Biotechnology Open-Ended Project (EBL2018002), and Fujian Science and Technology Guiding Project (2018Y0079). This study was also supported by the National Science Foundation (51520105013, 51679087), the 111 Program (B14008), and the Natural Science and Engineering Research Council of Canada. The authors deeply appreciate Dr. Yinghui Wu for his insightful comments and suggestions that have helped improve this paper substantially.

\section{References}

[1] X. Chen, G. Huang, M. Suo, H. Zhu, and C. Dong, "An inexact inventory-theory-based chance-constrained programming model for solid waste management," Stochastic Environmental Research and Risk Assessment, vol. 28, no. 8, pp. 1939-1955, 2014.

[2] B. Gu, S. Jiang, H. Wang et al., "Characterization, quantification and management of China's municipal solid waste in spatiotemporal distributions: a review," Waste Management, vol. 61, pp. 67-77, 2017.
[3] A. Lancia, D. Karatza, D. Musmarra, and F. Pepe, "Adsorption of mercuric chloride from simulated incinerator exhaust gas by means of Sorbalit ${ }^{\mathrm{TM}}$ particles," Journal of Chemical Engineering of Japan, vol. 29, no. 6, pp. 939-946, 1996.

[4] A. Di Nardo, I. Bortone, S. Chianese et al., "Odorous emission reduction from a waste landfill with an optimal protection system based on fuzzy logic," Environmental Science and Pollution Research, pp. 1-11, 2018.

[5] S. Paul, J. Li, R. Wheate, and Y Li, "Application of object oriented image classification and Markov chain modeling for land use and land cover change analysis," Journal of Environmental Informatics, vol. 31, no. 1, pp. 30-40, 2018.

[6] G. Tavares, Z. Zsigraiová, and V. Semiao, "Multi-criteria GISbased siting of an incineration plant for municipal solid waste," Waste Management, vol. 31, no. 9-10, pp. 1960-1972, 2011.

[7] A. Tayyebi, A. H. Tayyebi, B. K. Pekin, H. Omrani, and B. C. Pijanowski, "Modeling historical land use changes at a regional scale: applying quantity and locational error metrics to assess performance of an artificial neural network-based back-cast model," Journal of Environmental Informatics (JEI), vol. 31, no. 2, pp. 74-86, 2018.

[8] N. Milosevic, N. I. Thomsen, R. K. Juhler, H.-J. Albrechtsen, and P. L. Bjerg, "Identification of discharge zones and quantification of contaminant mass discharges into a local stream from a landfill in a heterogeneous geologic setting," Journal of Hydrology, vol. 446-447, pp. 13-23, 2012.

[9] D. Smahi, O. E. Hammoumi, and A. Fekri, "Assessment of the impact of the landfill on groundwater quality: a case study of the Mediouna Site, Casablanca, Morocco," Journal of Water Resource and Protection, vol. 5, no. 4, pp. 440-445, 2013.

[10] A. Erto, I. Bortone, A. Di Nardo, M. Di Natale, and D. Musmarra, "Permeable adsorptive barrier (PAB) for the remediation of groundwater simultaneously contaminated by some chlorinated organic compounds," Journal of Environmental Management, vol. 140, pp. 111-119, 2014.

[11] X. Jia, S. Wang, Z. Li, F. Wang, R. R. Tan, and Y. Qian, "Pinch analysis of GHG mitigation strategies for municipal solid waste management: a case study on Qingdao City," Journal of Cleaner Production, vol. 174, pp. 933-944, 2018.

[12] L. Liu, G. Huang, B. Baetz, C. Z. Huang, and K. Zhang, "A factorial ecologically-extended input-output model for analyzing urban GHG emissions metabolism system," Journal of Cleaner Production, vol. 200, pp. 922-933, 2018.

[13] W. Li, Z. Bao, G. H. Huang, and Y. L. Xie, "An inexact credibility chance-constrained integer programming for greenhouse gas mitigation management in regional electric power system under uncertainty," Journal of Environmental Informatics (JEI), vol. 31, no. 2, pp. 111-122, 2018.

[14] L. A. Guerrero, G. Maas, and W. Hogland, "Solid waste management challenges for cities in developing countries," Waste Management, vol. 33, no. 1, pp. 220-232, 2013.

[15] Y. Guan, G. Huang, L. Liu, C. Z. Huang, and M. Zhai, "Ecological network analysis for an industrial solid waste metabolism system," Environmental Pollution, vol. 244, pp. 279-287, 2019.

[16] X. Chen, G. Huang, H. Zhu, M. Suo, and C. Dong, "Inexact inventory theory-based waste management planning model for the City of Xiamen, China," Journal of Environmental Engineering, vol. 142, no. 5, p. 04016013, 2016.

[17] W. Huang, B. W. Baetz, and S. Razavi, "A GIS-based integer programming approach for the location of solid waste collection depots," Journal of Environmental Informatics (JEI), vol. 28, no. 1, pp. 39-44, 2016. 
[18] M. A. Shirazi, R. Samieifard, M. A. Abduli, and B. Omidvar, "Mathematical modeling in municipal solid waste management: case study of Tehran," Journal of Environmental Health Science and Engineering, vol. 14, no. 1, p. 8, 2016.

[19] V. Yadav, A. K. Bhurjee, S. Karmakar, and A. K. Dikshit, "A facility location model for municipal solid waste management system under uncertain environment," Science of the Total Environment, vol. 603-604, pp. 760-771, 2017.

[20] J. Garibay-Rodriguez, M. G. Laguna-Martinez, V. RicoRamirez, and J. E. Botello-Alvarez, "Optimal municipal solid waste energy recovery and management: a mathematical programming approach," Computers \& Chemical Engineering, vol. 119, pp. 394-405, 2018.

[21] S. Jia, X. Liu, and G. Yan, "Dynamic analysis of construction and demolition waste management model based on system dynamics and grey model approach," Clean Technologies and Environmental Policy, vol. 20, no. 9, pp. 2089-2107, 2018.

[22] G. M. Hoang, T. Fujiwara, T. S. P. Phu, and L. D. Nguyen, "Sustainable solid waste management system using multiobjective decision-making model: a method for maximizing social acceptance in Hoi An city, Vietnam," Environmental Science and Pollution Research, pp. 1-11, 2018.

[23] H. Zhu and G. H. Huang, "SLFP: a stochastic linear fractional programming approach for sustainable waste management," Waste Management, vol. 31, no. 12, pp. 2612-2619, 2011.

[24] I. S. Antonopoulos, G. Perkoulidis, D. Logothetis, and C. Karkanias, "Ranking municipal solid waste treatment alternatives considering sustainability criteria using the analytical hierarchical process tool," Resources, Conservation \& Recycling, vol. 86, pp. 149-159, 2014.

[25] X. Chen, G. Huang, H. Fu et al., "Allelopathy inhibitory effects of Hydrodictyon reticulatum on Chlorella pyrenoidosa under coculture and liquor-cultured conditions," Water, vol. 9, no. 6, p. 416, 2017.

[26] Q. Xu, Q. W. Chen, S. P. Zhao, K. Liu, and J. F. Ma, "Saving water and associated energy from distribution networks by considering landscape factors in pressure management and use of district metered areas," Journal of Environmental Informatics (JEI), vol. 31, no. 1, pp. 65-73, 2017.

[27] X. Chen, G. Huang, C. An, Y. Yao, and S. Zhao, "Emerging $\mathrm{N}$-nitrosamines and $\mathrm{N}$-nitramines from amine-based postcombustion $\mathrm{CO}_{2}$ capture - a review," Chemical Engineering Journal, vol. 335, pp. 921-935, 2018.

[28] G. Cheng, G. Huang, C. Dong et al., "Resources and environmental systems management under synchronic interval uncertainties," Stochastic Environmental Research and Risk Assessment, vol. 32, no. 2, pp. 435-456, 2018.

[29] P. Li, H. J. Wu, and B. Chen, "RSW-MCFP: a resource-oriented solid waste management system for a mixed rural-urban area through Monte Carlo simulation-based fuzzy programming," Mathematical Problems in Engineering, vol. 2013, Article ID 780354, 15 pages, 2013.

[30] X. Chen, G. Huang, S. Zhao, G. Cheng, Y. Wu, and H. Zhu, "Municipal solid waste management planning for Xiamen City, China: a stochastic fractional inventory-theory-based approach," Environmental Science and Pollution Research, vol. 24, no. 31, pp. 24243-24260, 2017.

[31] M. D. Toksari, “Taylor series approach to fuzzy multiobjective linear fractional programming," Information Sciences, vol. 178, no. 4, pp. 1189-1204, 2008.
[32] P. Guo, X. Chen, M. Li, and J. Li, "Fuzzy chance-constrained linear fractional programming approach for optimal water allocation," Stochastic Environmental Research and Risk Assessment, vol. 28, no. 6, pp. 1601-1612, 2014.

[33] C. Z. Huang, S. Nie, L. Guo, and Y. R. Fan, "Inexact fuzzy stochastic chance constraint programming for emergency evacuation in Qinshan nuclear power plant under uncertainty," Journal of Environmental Informatics (JEI), vol. 30, no. 1, pp. 6378, 2017.

[34] C. Zhang, B. A. Engel, P. Guo et al., "Double-sided stochastic chance-constrained linear fractional programming model for managing irrigation water under uncertainty," Journal of Hydrology, vol. 564, pp. 467-475, 2018.

[35] H. Zhu and G. Huang, "Dynamic stochastic fractional programming for sustainable management of electric power systems," International Journal of Electrical Power \& Energy Systems, vol. 53, pp. 553-563, 2013.

[36] F. Chen, G. Huang, Y. Fan, and R. F. Liao, "A nonlinear fractional programming approach for environmental-economic power dispatch," International Journal of Electrical Power \& Energy Systems, vol. 78, pp. 463-469, 2016.

[37] C. Zhang and P. Guo, "A generalized fuzzy credibilityconstrained linear fractional programming approach for optimal irrigation water allocation under uncertainty," Journal of Hydrology, vol. 553, pp. 735-749, 2017.

[38] L. Wang, G. Huang, X. Wang, and H. Zhu, "Risk-based electric power system planning for climate change mitigation through multi-stage joint-probabilistic left-hand-side chanceconstrained fractional programming: a Canadian case study," Renewable \& Sustainable Energy Reviews, vol. 82, pp. 1056-1067, 2018.

[39] Xiamen Statistics, Xiamen Special Economic Zone Yearbook, 2015.

[40] Xiamen Statistics, Xiamen Special Economic Zone Yearbook, 2016.

[41] Xiamen Municipal Bureau of Environment Protection, "Information announcement of Xiamen municipal solid waste pollution prevention and control," 2016.

[42] A. Mani, F. T.-C. Tsai, and K. P. Paudel, "Mixed integer linear fractional programming for conjunctive use of surface water and groundwater," Journal of Water Resources Planning and Management, vol. 142, no. 11, p. 04016045, 2016.

[43] P. Q. Gao, "Management and integrated treatment planning of municipal domestic waste in Xiamen City," Environmental Sanitation Engineering, vol. 15, no. 5, pp. 8-11, 2007 (Chinese).

[44] Xiamen Municipal Bureau of Environment Protection, "Information announcement of Xiamen municipal solid waste pollution prevention and control," 2013. 


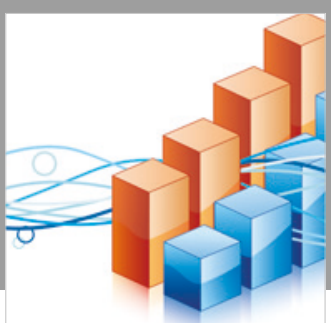

Advances in

Operations Research

\section{-n-m}
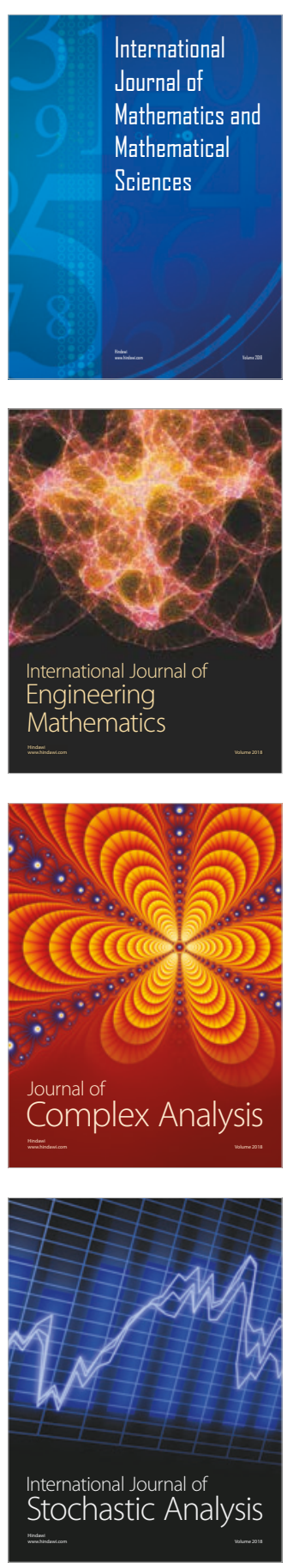
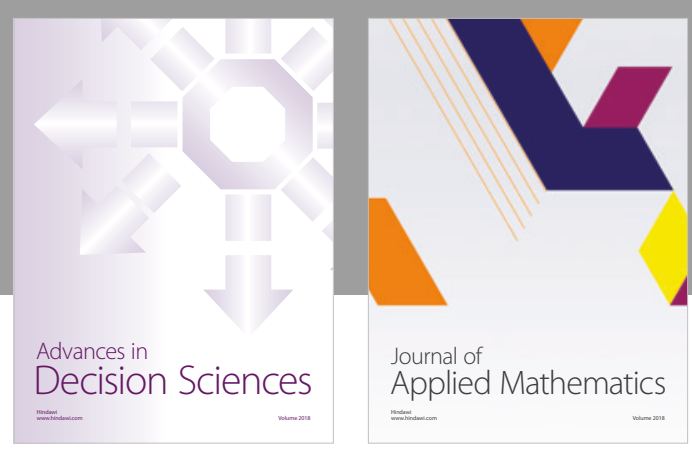

Journal of

Applied Mathematics
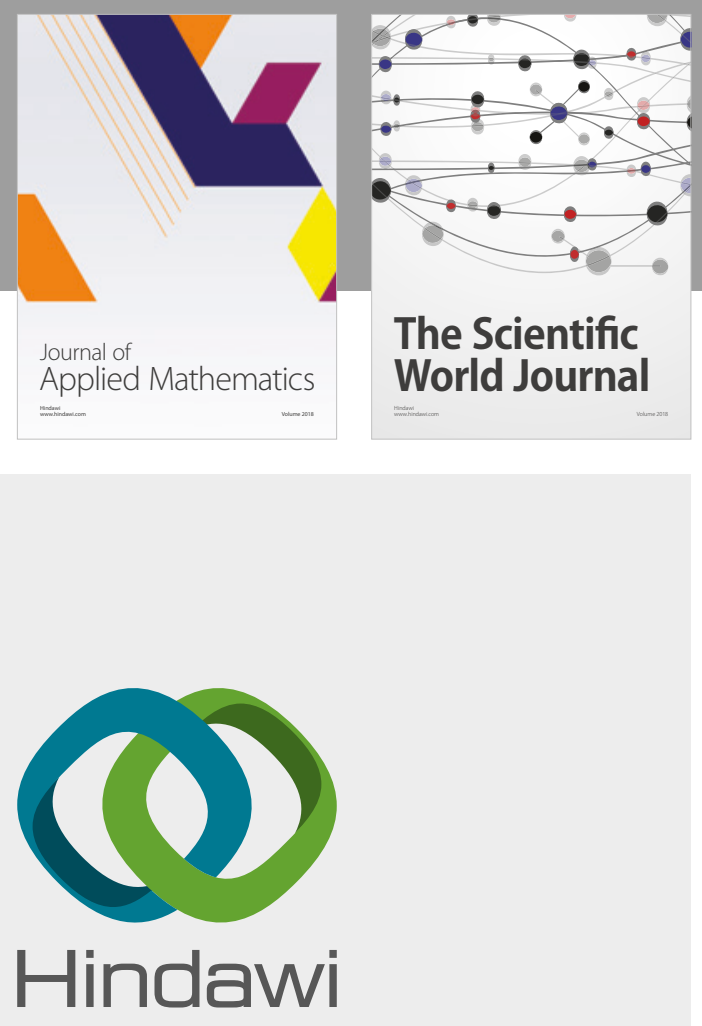

Submit your manuscripts at

www.hindawi.com

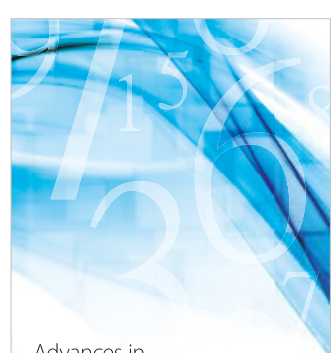

Advances in
Numerical Analysis
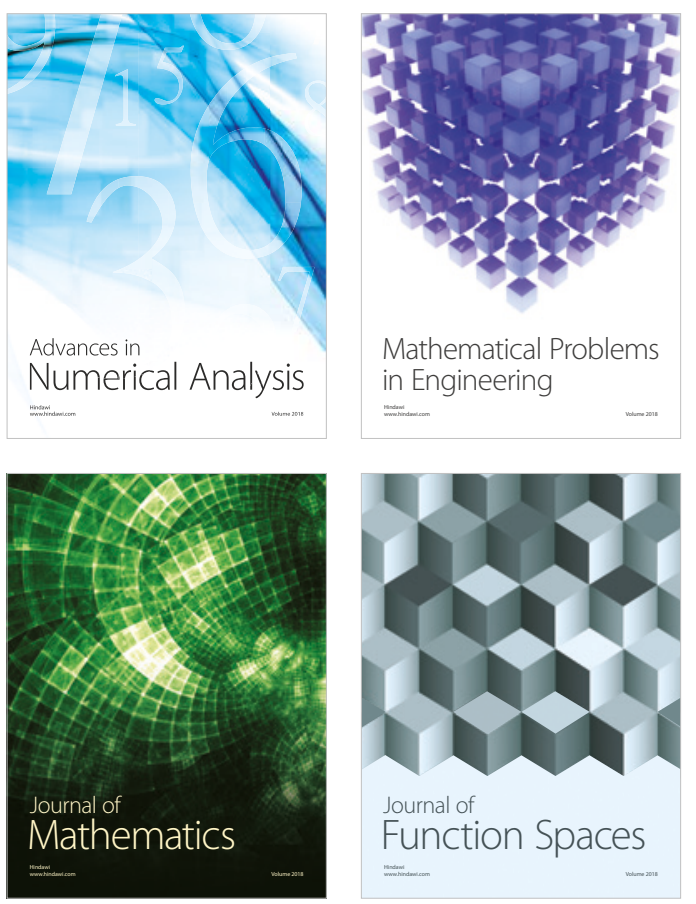

Mathematical Problems in Engineering

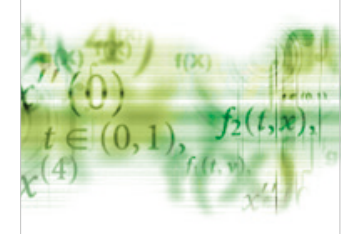

International Journal of

Differential Equations

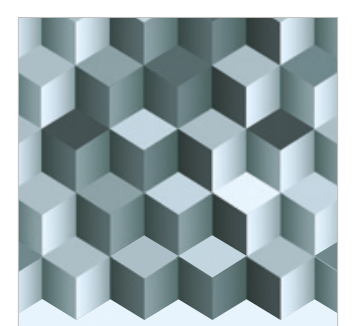

Journal of

Function Spaces

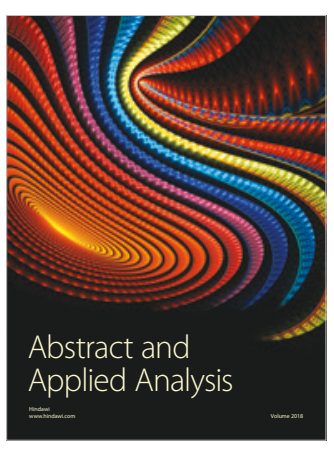

The Scientific

World Journal

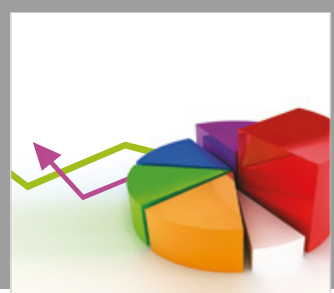

Journal of

Probability and Statistics
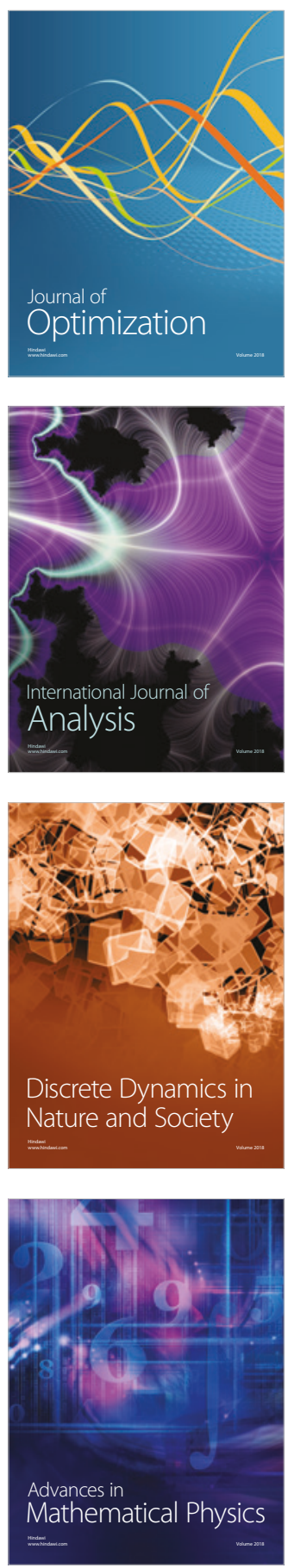